\title{
Seawater Exchange and Residence Time in Gamak Bay Determined by Numerical Experiments
}

\author{
Moon Ock Lee* and Byeong Kuk Kim \\ Depatment of Marine Architecture and Ocean Engineering, Chonnam National University, Yeosu 550-749, Korea
}

\begin{abstract}
We conducted modeling experiments to evaluate the residence times and exchange rates of seawater in Gamak Bay, located on the southern coast of the Korean Peninsula. The results revealed that pollutants are more quickly dispersed in a fixed grid rather than in a variable grid system. Pollutant concentrations decayed exponentially with time after release near the mouth of the bay, whereas no exponential variations were seen at the northwest end of the bay. The mean exchange rate of the seawater was $1.58 \%$ per day in the variable grid system, and the residence time of pollutants was greater than 288 days in Gamak Bay. Conversely, the exchange rate of seawater in Gamak Bay, as revealed by the particle tracking method, was $65 \%$ over a 50-day simulation. The results suggest that the seawater exchange in Gamak Bay is so low that pollutants are likely to remain in the bay indefinitely.
\end{abstract}

Key words: Seawater exchange, Residence time, Gamak Bay, Fixed grid, Variable grid, Particle tracking

\section{Introduction}

Gamak Bay, which lies at the southernmost tip of the Korean Peninsula, is an oval, semi-enclosed shallow body of water with a mean depth of $9 \mathrm{~m}$ and surface area of approximately $112 \mathrm{~km}^{2}$. The bay has two channels, one at the northeast end and one at the southern end, as shown in Fig. 1. The bay is home to many commercially important marine organisms, such as oysters, akagai mussels, ark shells, rockfish, sea bream, and flounder. As of 2010, the entire fisheries production in this area accounted for approximately 5\% of Korea's total fish production (http://www.fips.go.kr; http:// www. yeosu.go.kr). Furthermore, the bay produces approximately one-third of the nationwide oyster supply. However, oyster production has declined from a peak of 9,600 t of wet meat in 1991 to $1,700 \mathrm{t}$ in 1994, and oyster production in this area is now considered threatened (Lee et al., 2009). In addition, harmful algal blooms, particularly of the dinoflagellate Cochlodinium polykrikoides have occurred almost every year since 1995, resulting in substantial damage to the fishing industry (http://www.nfrdi.re.kr). Therefore, measures must be taken toward restoring the marine environment, thereby improving the productivity of the fishing grounds in Gamak Bay. Numerous studies have examined the flow structure, water quality, fishing environment, and algal blooms in Gamak Bay (Lee and Chang, 1982; Lee, 1992; Lee et al., 1995, 2005, 2009, 2010; Yoon, 2000; Lee and Park, 2004; Kang and Kim, 2006). However, most of these studies, with the exceptions of Lee and Chang (1982) and Lee et al. (2006), failed to examine seawater exchange, which is an important component of a fishing environment. Here, we used a model to evaluate the conveyance of seawater through two channels in Gamak Bay, in an attempt to provide insight into the current marine environmental issues in this region. Specifically, we evaluated the seawater exchange using a particle tracking method in the northeast channel of the bay, which is only $300 \mathrm{~m}$ wide and characterized by coastal areas of complex topography that may facilitate particle trapping. We examined the effect of grid size on the seawater exchange, comparing the model results when a variable grid or a fixed grid system was employed.
Open Access http://dx.doi.org/10.5657/FAS.2011.0421

This is an Open Access article distributed under the terms of the Creative Commons Attribution Non-Commercial License (http://creativecommons. org/licenses/by-nc/3.0/) which permits unrestricted non-commercial use, distribution, and reproduction in any medium, provided the original work is properly cited. pISSN: 2234-1749 eISSN: 2234-1757
Received 13 July 2011; Revised 5 October 2011; Accepted 16 November 2011

*Corresponding Author

E-mail: leemo@jnu.ac.kr 


\section{Materials and Methods}

The numerical model used was the Environmental Fluids Dynamics Code (EFDC), which was developed by the Virginia Institute of Marine Science, and authorized by Environmental Protection Agency of the United States. The EFDC has been successfully used to examine many aspects of marine environments, including assessments of dilution effects due to the fresh water in the James and York rivers (Hamrick, 1992a, 1992b, 1995a); movements of juvenile oyster and larvae (Hamrick, 1994); an assessment of the impacts of dredging work (Hamrick, 1995b); evaluations of saline water intrusion in the Indian River Lagoon (Moustafa and Hamrick, 1994); a large scale wetland simulation in the Everglades (Moustafa and Hamrick, 2000), a water-quality assessment of Pyeongtack Harbor (Lee, 2005); and model simulations of tide, tidal current and suspended load transport in the southern and western coastal waters of Korea (Kwon and Kang, 2007; Park, 2008). The EFDC uses measurements of three-dimensional static pressure, free water surface, and vertically averaged turbulence motion to generate equations representing variable density flows. It can also use a variety of coordinate systems, such as stretched, vertically $\sigma$ coordinates and Cartesian or curvilinear orthogonal coordinates. In addition, the EFDC allows several Eulerian transport equations to be simultaneously solved to obtain solutions for solute and suspended materials, and can evaluate particle transport using the Lagrangian method. In this study, the computational domain consisted of rectangular grid nets of $64 \mathrm{~km}$ east-westward and $77 \mathrm{~km}$ south-northward, as indicated in Fig. 2. In a fixed grid system, the spatial intervals are given equal values of $200 \mathrm{~m}$, whereas these values vary from $100 \mathrm{~m}$ to $800 \mathrm{~m}$ in a variable grid system. The time interval was held constant at 5 seconds in both the variable and fixed grid systems. For model verification, we used previously reported tide and current data (Lee and Park, 2004; Lee et al., 2005) as well as data from the Korea Hydrographic and Oceanographic Administration (http://www.khoa. go.kr).

The four major components of the tide, $\mathrm{M}_{2}, \mathrm{~S}_{2}, \mathrm{~K}_{1}$ and $\mathrm{O}_{1}$, were considered as open boundary conditions. To evaluate the seawater exchange in the bay, we set the initial concentration of the virtual pollutant to be $1.0 \mathrm{mg} / \mathrm{L}$ at all areas of Gamak Bay, which were enclosed by cross sections A-A' and B-B', as indicated in Fig. 1, while the outside of the bay was set to 0.0 $\mathrm{mg} / \mathrm{L}$. The simulation was initiated during the first high-water of the spring tide and run for 50 days. The seawater exchange for Gamak Bay was evaluated in two ways: first by temporal variations of pollutant concentration and second by the random walk method developed by Lee and Kim (1995a, 1995b). For the random walk method, 11,588 particles were released from their initial positions within each grid inside the bay, and then counted to evaluate the exchange rates of seawater. Note that we predicted the movement of the particles to be representative of that of the seawater.

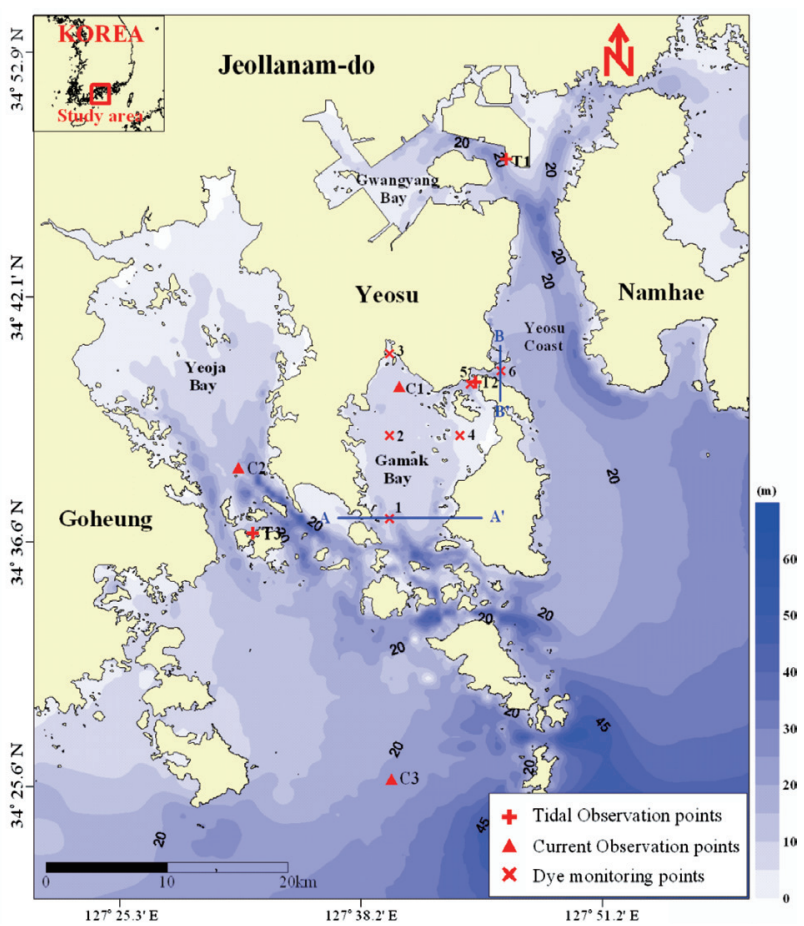

Fig. 1. Study area and oceanographic stations.

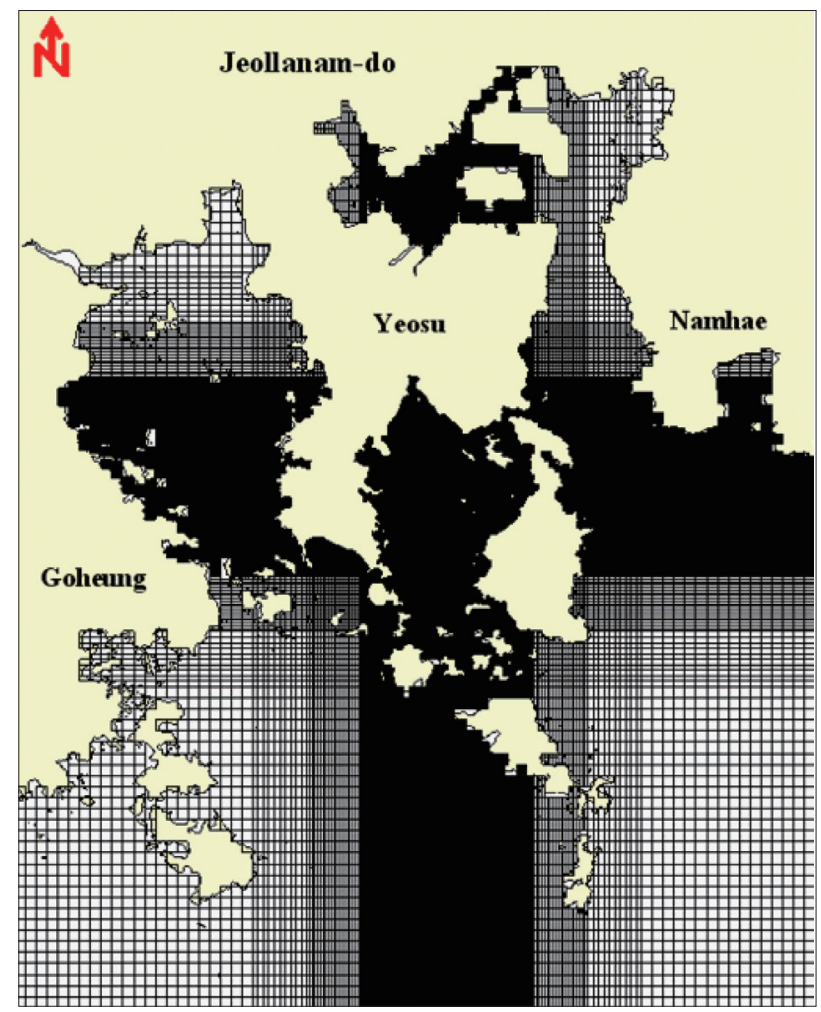

Fig. 2. Composition of computational domain in a variable grid system 
To determine the exchange rates of seawater, we used the following equation (Masan City, 2009):

$$
R_{D M}=1-\left(1-R_{n}\right)^{1 / n}=1-\left(\frac{c_{n}}{c_{0}}\right)^{1 / n}
$$

where $R_{\mathrm{DM}}$ is the exchange rate of seawater in a day, $R_{n}$ is the exchange rate of seawater for $n$ days, $c_{0}$ is the initial concentration, and $c_{n}$ is the concentration after $n$ days. Additionally, the exchange rate of seawater, $R_{\mathrm{E}}(\%)$, in the particle tracking method, was expressed by the following equation (Lee et al., 2006):

$$
\left.R_{E}(\%)=\left(P_{\text {initial }}-P_{\text {out }}\right) / P_{\text {initial }}\right) \times 100,
$$

where $P_{\text {initial }}$ is the initial number particles, and $P_{\text {out }}$ is the number of particles leaving the bay after an arbitrary time, $t$.

\section{Results and Discussion}

\section{Validation of the model and general flow patterns}

Table 1 lists the correlation coefficients between the computed and observed values obtained at stations T1-T3 for tides and $\mathrm{C} 1-\mathrm{C} 3$ for currents. The computed tide values were highly

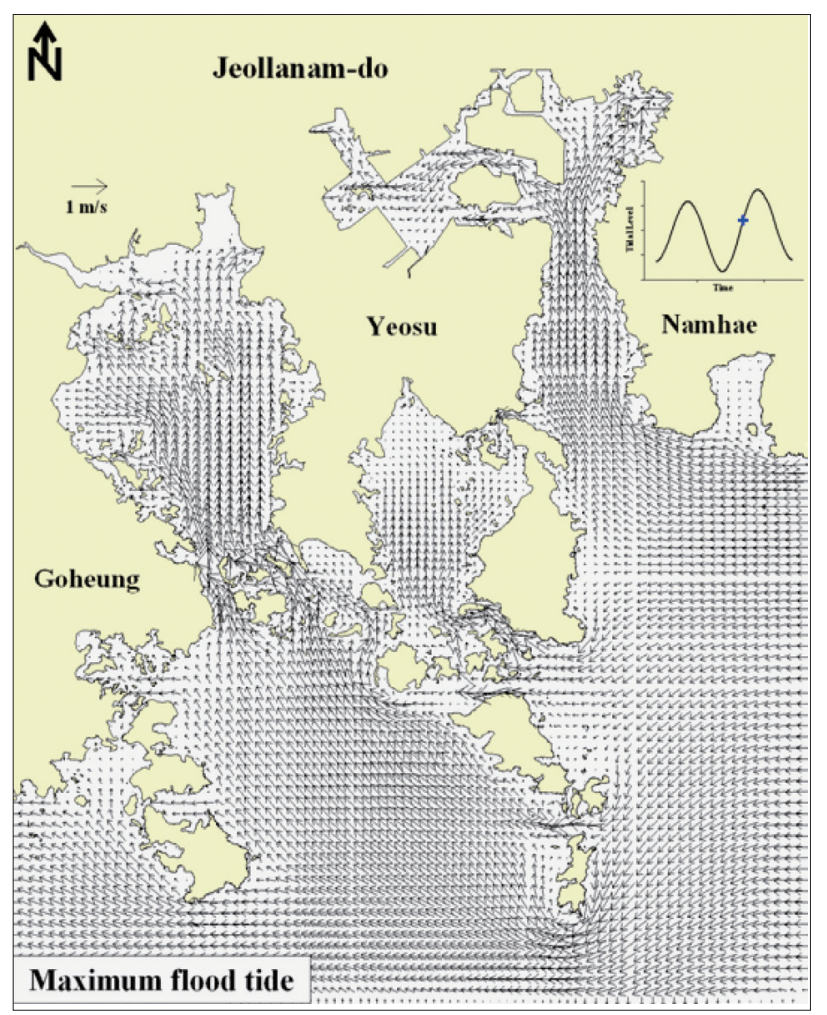

equivalent to the observed ones, and the computed and observed values for currents were sufficiently correlated, even though the correlation coefficients for the v-components were relatively low. Therefore, we concluded that the flow structure determined by the computational model domain was ideal. Fig. 3 shows the general flow patterns during the strongest flood and ebb tides in the spring. Note that the tidal currents inside Gamak Bay appeared inactive as a whole, except for in the vicinity of the two channels, and were particularly stagnant at the north part of the bay.

Table 1. Correlation coefficients between the observed and computed

\begin{tabular}{|c|c|c|c|}
\hline Tides & $\begin{array}{c}\text { Correlation } \\
\text { coefficient }\end{array}$ & Currents & $\begin{array}{c}\text { Correlation } \\
\text { coefficient }\end{array}$ \\
\hline \multirow{2}{*}{$\mathrm{T} 1$} & \multirow{2}{*}{1.000} & \multirow{2}{*}{$\mathrm{C} 1 \frac{\text { U-comp. }}{\text { V-comp. }}$} & 0.938 \\
\hline & & & 0.951 \\
\hline \multirow{2}{*}{$\mathrm{T} 2$} & \multirow{2}{*}{1.000} & \multirow{2}{*}{ C2 $\frac{\text { U-comp. }}{\text { V-comp. }}$} & 0.983 \\
\hline & & & 0.915 \\
\hline \multirow{2}{*}{$\mathrm{T} 3$} & \multirow{2}{*}{0.999} & \multirow{2}{*}{ C3 $\frac{\text { U-comp. }}{\text { V-comp. }}$} & 0.981 \\
\hline & & & 0.913 \\
\hline
\end{tabular}
tides and currents

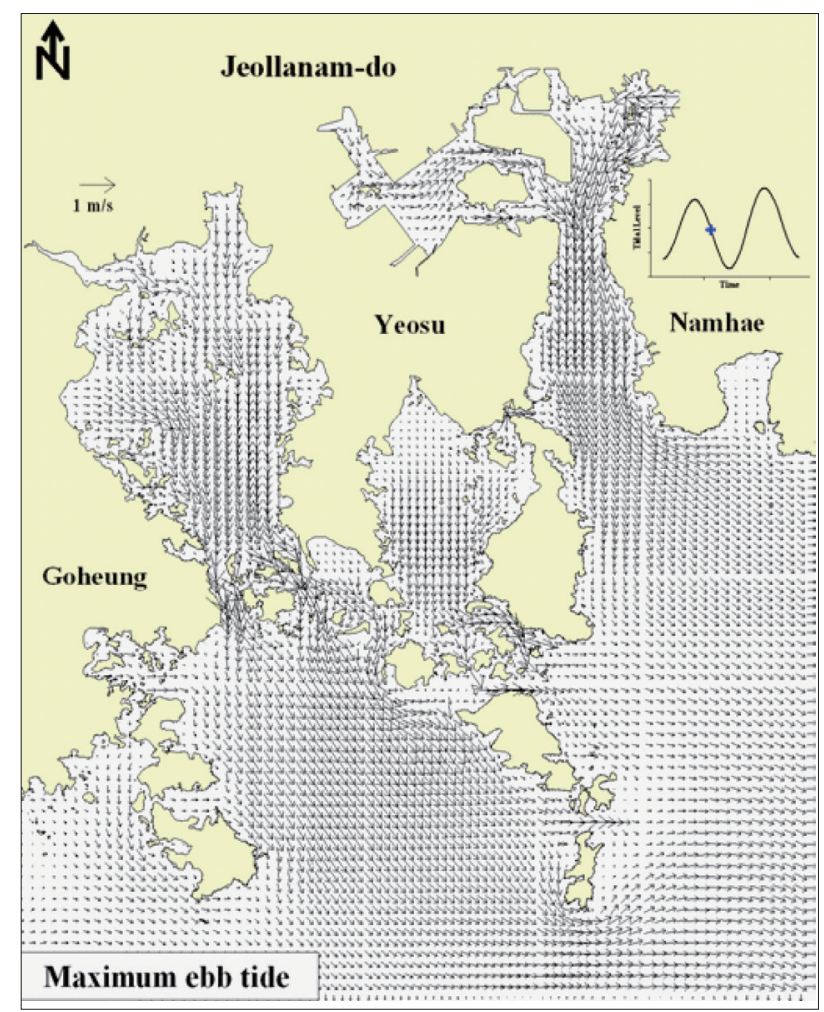

Fig. 3. General flow patterns of the strongest flood and ebb tides. 


\section{Seawater exchange rate and residence time for Gamak Bay}

Fig. 4 illustrates the temporal variations of pollutant concentration every 10 days after the initiation of dispersal, with the curves for each figure denoting isopleths of pollutant concentration. These results suggest that pollutants disperse mostly through the south channel. Qualitatively, this is in agreement with results of Lee and Chang (1982) and Lee (1992). Additionally, the mean concentration of pollutants in Gamak Bay was $0.335 \mathrm{mg} / \mathrm{L}$ in the fixed grid system and $0.432 \mathrm{mg} / \mathrm{L}$ in the variable grid system 50 days after the release of pollutants. Thus, the final concentrations of pollutants differed between the fixed and variable grid systems. This discrepancy could have occurred because the variable grid system is better able to reproduce the actual flow structure, particularly near the channels, because the northeast channel is too narrow to be accurately represented by one or two fixed grids of $200 \mathrm{~m}$, whereas the variable system allows a grid of $100 \mathrm{~m}$. Conversely, the fixed grid system predicted that the pollutant concentration was $0.667 \mathrm{mg} / \mathrm{L}$ at the northwest part of the bay, whereas the variable grid system predicted a value of $0.872 \mathrm{mg} / \mathrm{L}$ after 50 day simulations. Therefore, pollutants were predicted to disperse more quickly by the fixed grid system than the variable grid system. Table 2 lists the temporal variations in pollutant concentration computed using a three-dimensional model with the variable grid system. The lapse time indicates the number of days since pollutants entered the bay, and $\mathrm{S}$ and $\mathrm{B}$ denote the surface and bottom layers, respectively. The ST1 to ST6 represent cross sections between A-A' and B-B' or at the north of the bay for verification. The results of this simulation indicate that pollutant decayed quickly early in the dispersal process, whereas it slowed by the time the pollutants reached sites.ST1, ST5, and ST6, which are located at the mouths of the bay. Conversely, at points ST2, ST3, and ST4, which are located within the northern region of the bay, the dispersal rate was low at first and increased later in the dispersal process. Pollutants tended to disperse more quickly at the mouths of the bay. On average, the pollutant concentrations in Gamak Bay decreased to lower than $50 \%$ of the initial value over the 50- day simulation period.
The model predicted somewhat rhythmic variations in pollutant concentrations, particularly at points ST1, ST5, and ST6, which are located at the mouth of the bay. This is likely a reflection of tidal action. The results of the three-dimensional model predicted less effective dispersal than the two-dimensional model. However, no significant differences were observed in the temporal variations of concentration between the surface and bottom layers. The pollutant concentration was $0.031 \mathrm{mg} / \mathrm{L}$ at the cross section A-A', $0.028 \mathrm{mg} / \mathrm{L}$ at the cross

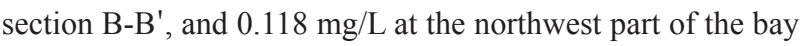
after 50 days. These results indicate that the northwest region of the bay experienced relatively low seawater exchange rates. Fig. 5 shows temporal variations in pollutant concentration at each point over the 50 days. These results indicate that the pollutant concentration decreased exponentially at the mouth of the bay (ST1, ST5, and ST6), whereas no exponential decay rate was observed in the northwest region of the bay (ST2, ST3, and ST4). Table 3 lists the mean exchange rates and residence times of seawater in Gamak Bay for 50 simulation days under different computational conditions, with 50\%, 90\%, and $99 \%$ representing the percentage of pollutants removed. The results indicate that the mean seawater exchange rates predicted using the variable grid system in a three-dimensional model were fairly low, resulting in the longest residence times.

Fig. 6 describes features of the 11,588 particles every 10 days after particle release. The particles leaving the northeast mouth of the bay first move northward, after which a portion of them migrate south while the particles leaving the southern mouth of the bay continue to move southward. The variable grid system predicted the exchange rate of seawater for Gamak Bay to be $65.1 \%$ within the surface layer and $64.5 \%$ within the bottom layer over 50 days, indicating a negligible difference between the two layers. Conversely, the average exchange rate predicted by the fixed grid system was $50.8 \%$, which is $14.0 \%$ lower than that predicted by the variable grid system. The discrepancy may have been a result of the different number of grids, since a variable grid system can deploy more particles at the mouth of the bay, thus facilitating the exchange of seawater.

So far we examined the seawater exchange through two channels and residence time in Gamak Bay using a modeling

Table 2. Temporal variations of pollutant concentration $(\mathrm{mg} / \mathrm{L})$ at each point of Gamak Bay

\begin{tabular}{|c|c|c|c|c|c|c|c|c|c|c|c|c|c|c|}
\hline \multirow{2}{*}{$\begin{array}{l}\text { Lapse time } \\
\quad \text { (day) }\end{array}$} & \multicolumn{2}{|c|}{ ST1 } & \multicolumn{2}{|c|}{ ST2 } & \multicolumn{2}{|c|}{ ST3 } & \multicolumn{2}{|c|}{ ST4 } & \multicolumn{2}{|c|}{ ST5 } & \multicolumn{2}{|c|}{ ST6 } & \multicolumn{2}{|c|}{ Gamak Bay } \\
\hline & S & B & $\mathrm{S}$ & B & $\mathrm{S}$ & B & S & B & $\mathrm{S}$ & B & $\mathrm{S}$ & B & S & B \\
\hline 1 & 0.42 & 0.44 & 1.00 & 1.00 & 1.00 & 1.00 & 1.00 & 1.00 & 0.47 & 0.49 & 0.11 & 0.12 & 0.90 & 0.90 \\
\hline 10 & 0.29 & 0.29 & 0.99 & 0.99 & 1.00 & 1.00 & 0.97 & 0.97 & 0.35 & 0.36 & 0.20 & 0.19 & 0.84 & 0.84 \\
\hline 20 & 0.25 & 0.25 & 0.93 & 0.93 & 1.00 & 1.00 & 0.77 & 0.77 & 0.21 & 0.21 & 0.08 & 0.08 & 0.70 & 0.70 \\
\hline 30 & 0.11 & 0.11 & 0.81 & 0.81 & 0.98 & 0.98 & 0.51 & 0.51 & 0.10 & 0.10 & 0.03 & 0.04 & 0.50 & 0.50 \\
\hline 40 & 0.12 & 0.12 & 0.77 & 0.77 & 0.95 & 0.95 & 0.45 & 0.45 & 0.12 & 0.13 & 0.08 & 0.07 & 0.50 & 0.51 \\
\hline 50 & 0.17 & 0.17 & 0.66 & 0.66 & 0.88 & 0.88 & 0.35 & 0.35 & 0.12 & 0.12 & 0.07 & 0.06 & 0.45 & 0.45 \\
\hline
\end{tabular}



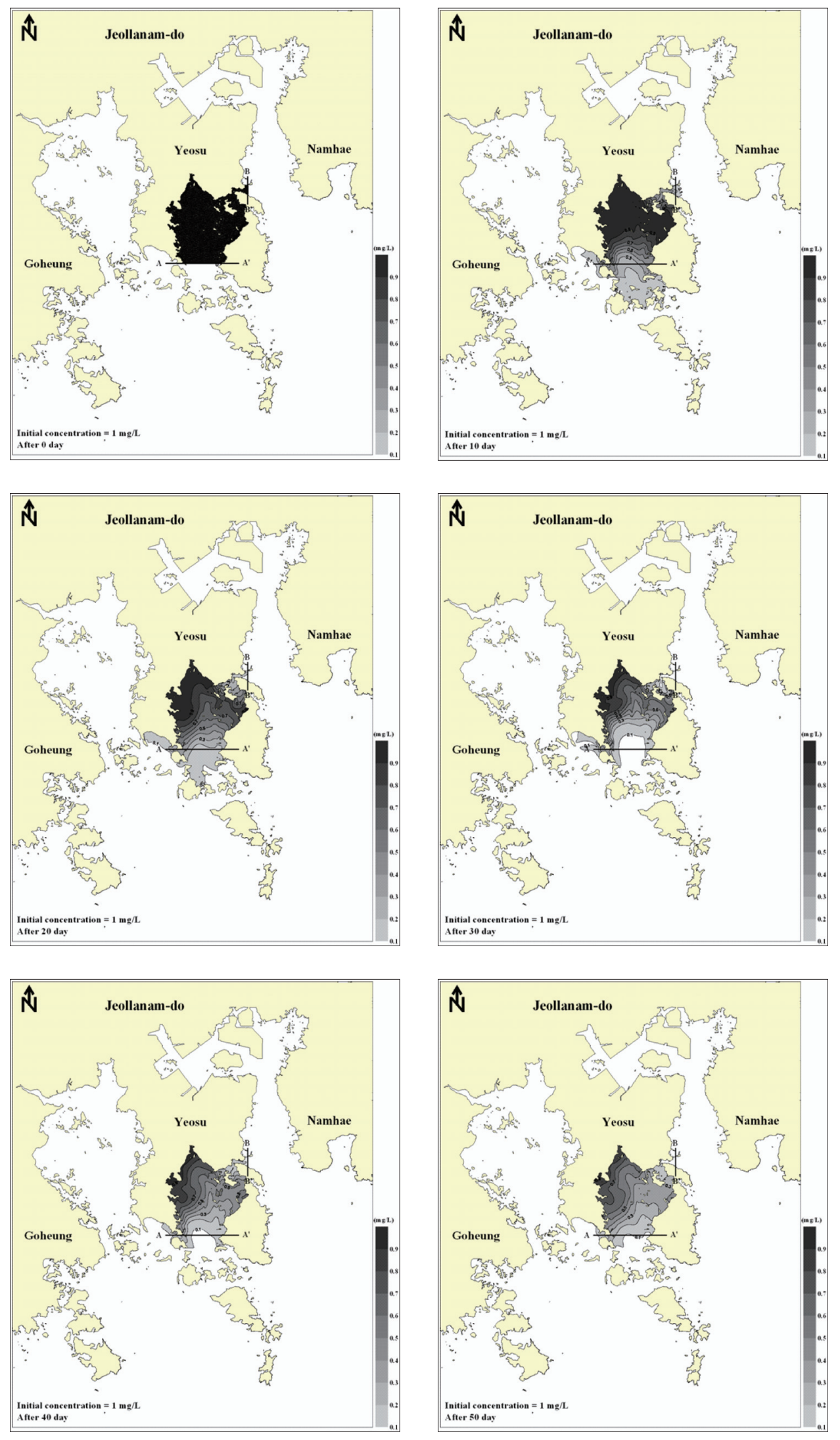

Fig. 4. Temporal variations of pollutant concentration for every ten day since the first release 

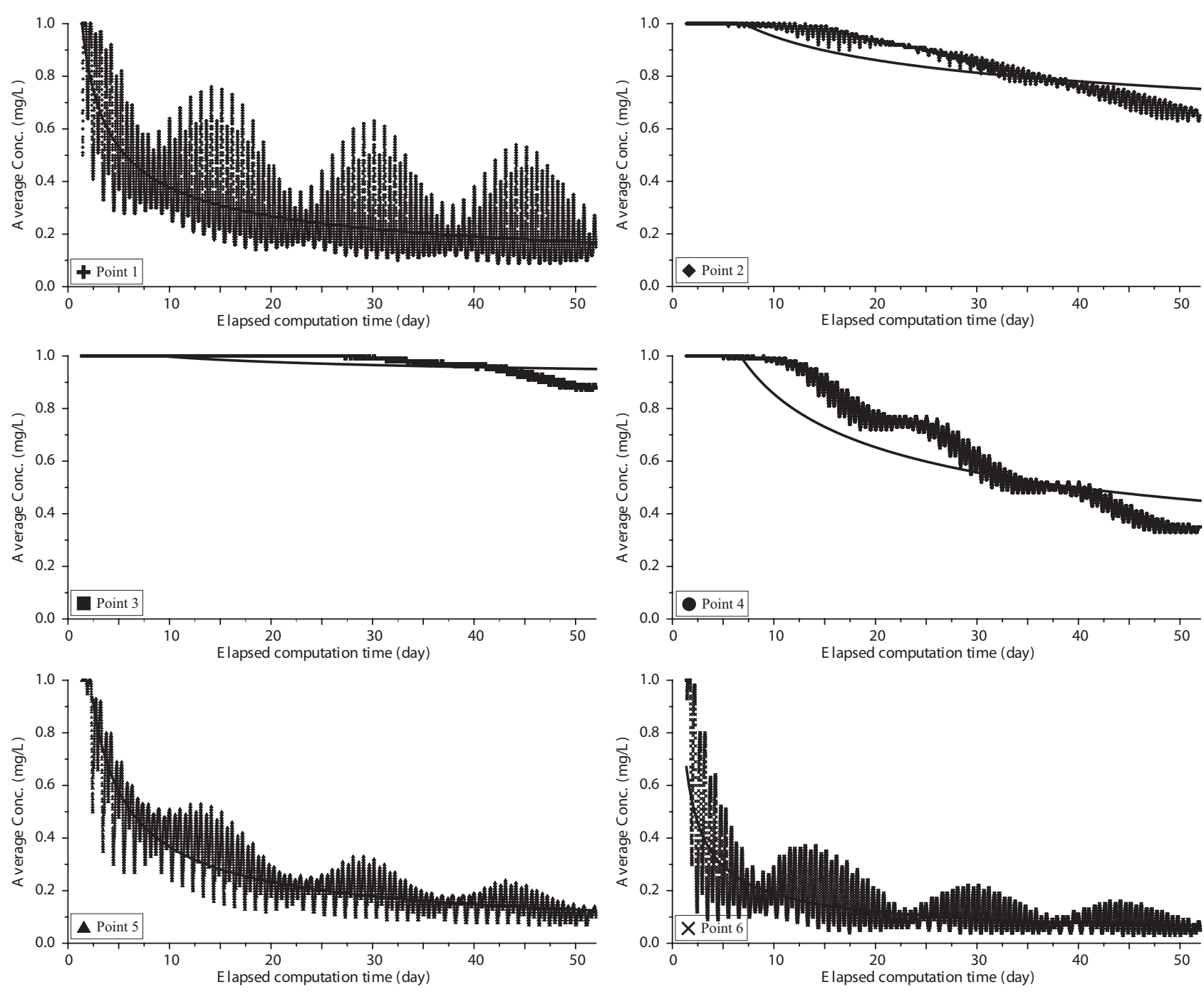

Fig. 5. Temporal variations of concentration at each point after the release of pollutant.

Table 3. Mean exchange rates per day and residence time of seawater for Gamak Bay

\begin{tabular}{llccccc}
\hline \multirow{2}{*}{ Location } & Case & \multicolumn{3}{c}{$\begin{array}{c}\text { Mean exchange rate } \\
\text { of seawater per day }\end{array}$} & \multicolumn{2}{c}{ Residence time (day) } \\
\cline { 5 - 7 } & & $\mathbf{( \% )}$ & $\mathbf{5 0 \%}$ & $\mathbf{9 0 \%}$ & $\mathbf{9 9 \%}$ \\
\hline \multirow{3}{*}{ Gamak Bay } & Fixed grid in 2D & 2.16 & 31.7 & 105.3 & 210.5 \\
& Variable grid in 2D & 1.66 & 41.3 & 137.2 & 274.3 \\
& Variable grid in 3D & 1.58 & 43.4 & 144.2 & 288.4 \\
\hline
\end{tabular}

system. As a result, the fixed model system predicted that the mean concentration of pollutants within Gamak Bay would decrease from $1.0 \mathrm{mg} / \mathrm{L}$ to $0.335 \mathrm{mg} / \mathrm{L}$ over 50 days, whereas the variable model system predicted a decrease to $0.432 \mathrm{mg} / \mathrm{L}$. Therefore, the fixed grid system predicted more rapid pollution dispersal. Our three-dimensional model predicted less effective dispersion than the two-dimensional model. The pollutant concentration decayed exponentially with time at the mouths of the bay, whereas this pattern was not observed in the northwest region of the bay. The mean exchange rate of seawater per day in Gamak Bay predicted by the three-dimensional model with a variable grid system was $1.58 \%$, suggesting a residence time greater than 288 days. The variable grid model predicted the exchange rate of seawater in Gamak Bay to be $65.1 \%$ after 50 days at the surface layer, whereas the fixed model predicted a $50.8 \%$ exchange rate. Taken together, the results of our model simulations suggest that the seawater exchange rate in Gamak Bay is insufficient to adequately remove pollutants, and thus that without drastic measures to eliminate pollutant input, the water quality will continue to decline. 

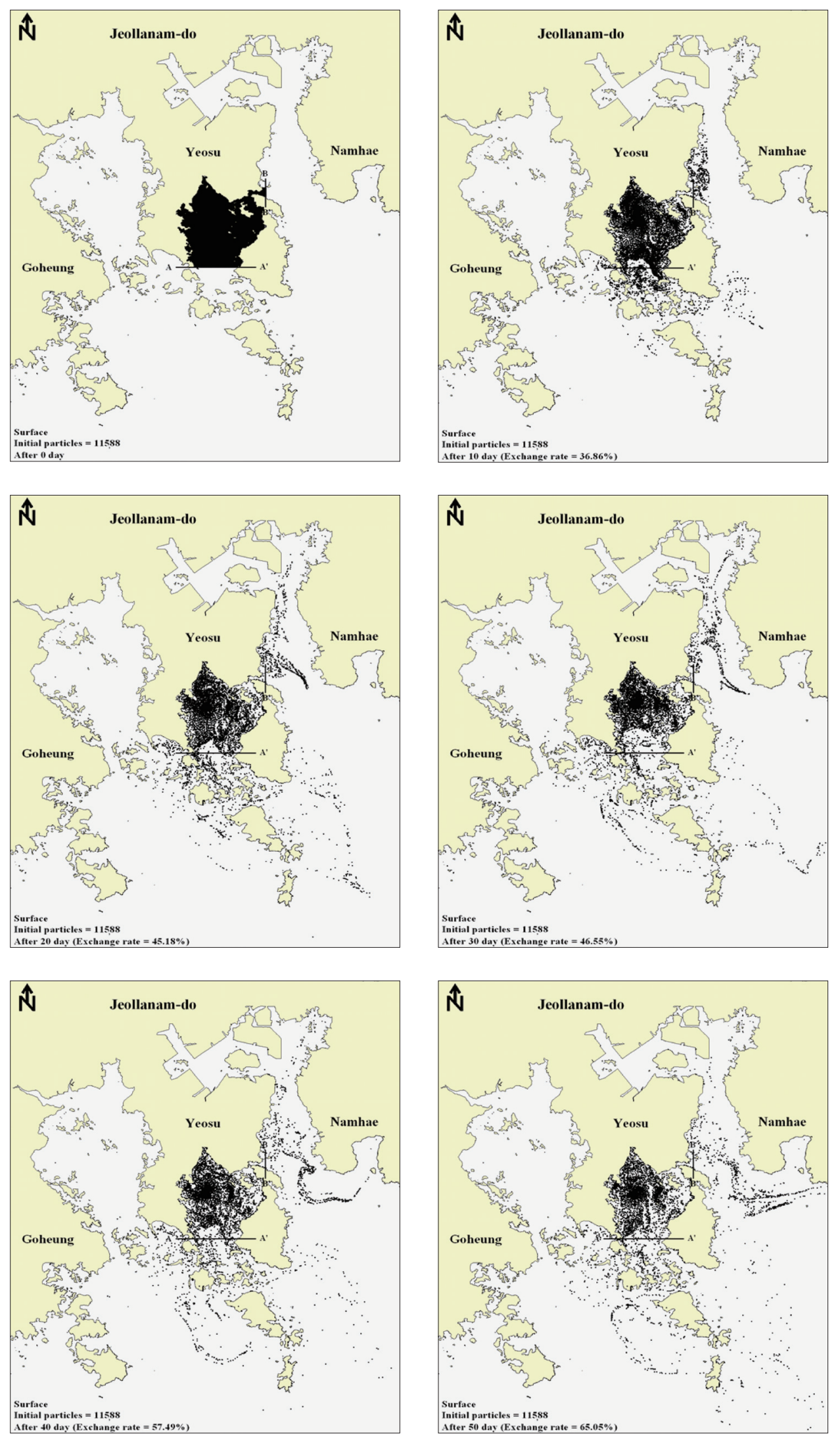

Fig. 6. Features of particles dispersing from their initial position for every 10 day during 50 days. 


\section{References}

Hamrick JM. 1992a. A Three-Dimensional Environmental Fluid Dynamics Computer Code : Theoretical and Computational Aspects, Special Report 317. The College of William and Mary, Virginia Institute of Marine Science, Gloucester Point, VA, US.

Hamrick JM. 1992b. Estuarine environmental impact assessment using a three-dimensional circulation and transport model. In: Estuarine and Coastal Modeling, Proceedings of the 2nd International Conference. Spauding ML, ed., American Society of Civil Engineers, New York, US, pp.292-303.

Hamrick JM. 1994. Evaluation of Island Creation Alternative in the Hampton Flats of the James River.: A Report to the US Army Corps of Engineers, Norfolk District. The College of William and Mary, Virginia Institute of Marine Science, Gloucester Point, VA, US.

Hamrick JM. 1995a. Calibration and Verification of the VIMS EFDC Model of the James River, Virginia. The College of William and Mary, Virginia Institute of Marine Science, Gloucester Point, VA, US.

Hamrick JM. 1995b. Evaluation of the Environmental Impacts of Channel Deeping and Dredge Spoil Site Expansion in the Lower James River, Virginia. The College of William and Mary, Virginia Institute of Marine Science, Gloucester Point, VA, US.

Kang H and Kim JG. 2006. The estimation of environmental capacity in the Gamak Bay using an eco-hydrodynamic model. J Environ Sci 15, 951-960.

Kwon SJ and Kang TS. 2007. Numerical simulation for behavior of tidal elevation and tidal currents in the south sea. J Korean Soc Coast and Ocean Eng 19, 253-265.

Lee GH. 1992. The pattern of sea water circulation in Kamak Bay. Bull Korean Fish Technol Soc 28, 117-131.

Lee JC, Choo HS, Lee KH and Cho KD. 1995. Tides and currents of Kamag Bay in July-August 1994. J Korean Fish Soc 28, 624-634.

Lee JS and Kim HJ. 1995a. Sensitivity analysis of diffusion solutions by random walk method. J Korean Soc Civil Eng 15, 1267-1277.

Lee JS and Kim HJ. 1995b. Tidal exchange ratio estimation by random walk method. In: Proceedings of the Annual Meeting for Korean
Society of Civil Engineers. Korean Society of Civil Engineers, Seoul, KR, pp.485-488.

Lee JW. 2005. Studies on the water quality simulation of reservoir using a three-dimensional EFDC model. Msc thesis, Chungnam National University, Daejeon, KR.

Lee M, Park SJ and Kang TS. 2006. Influence of reclamation works on the marine environment in a semi-enclosed bay. J Ocean Univ China, 5, 219-227.

Lee M, Kim B, Kwon Y and Kim J. 2009. Characteristics of the marine environment and algal blooms in Gamak Bay. Fish Sci 75, 401411.

Lee MC and Chang SD. 1982. Seawater exchange in Gamak Bay. J Korean Oceanol Soc 17, 12-18.

Lee MO and Park SJ. 2004. Wind effects on the oyster farm environment in Gamak Bay. J Fish Sci Technol 7, 204-214.

Lee MO, Kim BK, Park SJ and Kim JK. 2005. Some physical characteristics of Gamak Bay observed in October and November of year 2004. J Korean Soc Mar Environ Eng 8, 165-173.

Lee MO, Choi JH and Park IH. 2010. Outbreak conditions for Cochlodinium polykrikoides blooms in the southern coastal waters of Korea. Mar Environ Res 70, 227-238.

Masan City. 2009. Environmental Assessment Report on the Construction Projects of Masan Marine Mew town. Masan City, KR. pp.58465.

Moustafa MZ and Hamrick JM. 1994. Modeling circulation and salinity transport in the Indian River Lagoon. In: Estuarine and Coastal Modeling, Proceedings of 3rd International Conference. American Society of Civil Engineer, New York, US. pp.381-395.

Moustafa MZ and Hamrick JM. 2000. Calibration of the wetland hydrodynamic model to the Everglades nutrient removal project. Water Quality and Ecosystem Modeling 1, 141-167.

Park HY. 2008. Studies on transports of suspended solid induced by dredging in Daesan Port using the EFDC model. Msc thesis, Kunsan National University, Kunsan, KR.

Yoon YH. 2000. Variational characteristics of water quality and chlorophyll $a$ concentration in the northern part of Kamak Bay, southern Korea. J Korean Environ Sci Soc 9, 429-436. 